\title{
A Escola e seus Desafios na Contemporaneidade
}

Ana Ivenicki ${ }^{a}$

Como lidar com situações intra-escolares de indisciplina, exclusão, conflitos culturais e violência? Como promover processos de alfabetização e educação que valorizem a diversidade e a melhoria educacional para todos os alunos? De que modo políticas públicas e pesquisas têm se voltado a esses desafios?

Tais questões são complexas e refletem fatores que extrapolam, em muito, os espaços das escolas. Entretanto, potencializar atores escolares para o enfrentamento positivo dos dilemas da educação, nos espaços possíveis de suas atuações, pode vir a representar um dos caminhos promissores para mitigar conflitos e contribuir para a inclusão educacional, ainda que tal perspectiva deva ser complementada por ações de mais amplo espectro.

Autores tais como Candau \& Moreira (2012), Ivenicki (2018), Lopes (2012) e Ranniery e Macedo (2018), dentre outros, vêm postulando que o currículo inclui não apenas metodologias e listagens de conteúdos, mas todos os aspectos que fazem parte do cotidiano escolar. Da mesma forma, sugerem que os discursos de políticas educacionais, por si só, apresentam diretrizes que devem ser problematizadas, particularmente levando em conta as formas pelas quais as diferenças são aí retratadas ou invisibilizadas, com reflexos para a própria definição do significado da democracia.

Ao mesmo tempo, tais políticas, produzidas em contextos macro-estruturais, vêm a ser hibridizadas, recontextualizadas e ressignificadas nos diversos níveis meso (por exemplo,

de secretarias estaduais e municipais de educação ) e micro (nos projetos políticopedagógicos e nas práticas docentes), com significados plurais e locais, que devem ser levados em conta nas análises, bem como em processos de formação continuada de atores educacionais, centrais em sua implementação.

a Universidade Federal do Rio de Janeiro, Rio de Janeiro, RJ, Brasil. 
De fato, na perspectiva mais ampla do currículo, tem sido destacada a necessidade de se lidar com a diversidade cultural de forma positiva, diversidade esta que incide sobre variáveis de gênero, orientação sexual, raça, etnia, padrões religiosos, deficiências e outros, incluindo, ainda, a questão das identidades de imigrantes e refugiados no contexto educacional contemporâneo. Tal perspectiva coloca, mais uma vez, em xeque, qualquer normatividade política que se assente sobre o horizonte de uma universalidade a-priorística, ignorando a pluralidade, o local, o singular.

A ressignificação das políticas na vida das escolas e em outras instituições educacionais passa a ser percebida como aquela em que os potenciais de todos são incentivados, focalizando os atores educacionais como protagonistas de um movimento que desafie preconceitos, assédios e quaisquer formas de violência, racismos, sexismos, bullying e outros abusos, de modo a que se contribua para a formação de identidades comprometidas com direitos humanos, com a pluralidade e com valores democráticos de cidadania.

Políticas voltadas a escolas e grupos vulneráveis, no Brasil e no exterior, são, assim, intenções que passam a se tornar realidade na pluralidade institucional a níveis meso e micro, sendo o currículo compreendido como envolvendo esta pluralidade de significados, culturas e visões de mundo aí presentes.

As complexidades envolvidas nas teias de tradução/hibridização/recontextualização de tais políticas voltadas, em suas intenções declaradas, para a justiça social e para a inclusão educacional, são abordadas, sob ângulos e referenciais teórico-metodológicos diversos, nos artigos deste número 102 da Revista Ensaio. Os artigos apresentados no presente número são plurais, com referenciais e metodologias diversificados, mas que, de forma ora mais explícita ou de modo indireto, acabam por mostrar preocupações com a educação inclusiva e de qualidade para todos.

"Conflitos em Escolas Públicas em Portugal: análise de um programa de governo" examina um programa de governo adotado em Portugal que seleciona escolas públicas que atendem a grupos vulneráveis, buscando vislumbrar seus propósitos, impactos e percepções dos atores escolares envolvidos.

“ Dos Castigos Escolares à Construção dos Sujeitos de Direito: contribuições de políticas de diretos humanos para uma cultura da paz nas instituições educativas" aborda, em uma perspectiva histórica, a necessidade de um clima humanístico no trato com a diversidade estudantil nas escolas. Analisa documentos históricos que 
mostram o uso de castigos corporais e morais a estudantes nas escolas brasileiras dos séculos passados, enfatizando, a partir do olhar dos direitos humanos, a humilhação proporcionada pelos mesmos.

“O Pacto Nacional pela Alfabetização na Idade Certa Em Ação: revisão da literatura" apresenta uma análise de sessenta e quatro trabalhos que foram produzidos entre 2013 e 2016 sobre o Pacto Nacional pela Alfabetização na Idade Certa (PNAIC). Os trabalhos foram selecionados a partir de bancos de dados que incluíram o Banco de Teses e Dissertações da CAPES, Plataforma Sucupira, Portal de Periódicos CAPES, Scientific Electronic Library Online (Scielo) e em sites de eventos científicos, tendo sido critério de inclusão o de que fossem estudos empíricos, seja com base em pesquisas de campo ou documentais.

"Models for the Pedagogical Integration of Information and Communication Technologies: a literature review" - examina formas pelas quais a cultura tecnológica tem sido interpretada e incorporada por professores de escolas na Rússia. Reforça a ideia de que vivemos em um mundo cada vez mais informatizado, mas argumenta que tal fato não exime docentes da responsabilidade pelo planejamento e desenvolvimento das atividades pedagógicas com os alunos, assim como de seu protagonismo e liderança no processo educacional.

"La Experimentación Pedagógica Territorial y la Democratización del sistema educativo: lecciones del Plan Experimental de Educación rural de San Carlos (1944-1947) " apresenta uma pesquisa histórica que mergulha na memória para analisar uma experiência política a nível meso, em um estado chileno, considerada democratizadora e descentralizada, de apoio a grupos marginalizados, desta feita pertencentes ao mundo rural.

"Redes regionais para acreditação e avaliação da qualidade da educação superior" apresenta uma categorização de redes regionais de avaliação e acreditação, explorando aspectos de funcionamento de duas redes, de modo a reconhecer suas finalidades e alcances sociais e propor formas pelas quais podem representar movimentos contra-hegemônicos avaliativos.

"A Model of Personal -Oriented Training of Bachelors of Technical Profile for High Tech Industries" aborda, de forma mais implícita do que explícita, o tema do presente número da revista Ensaio referente a políticas e projetos educacionais voltados a grupos marginalizados. Aponta a necessidade de garantir condições de empregabilidade de grupos que completam sua formação universitária, porém cujas competências não correspondem ao que é esperado pelas indústrias. 
- “ Taxas Longitudinais de Retenção e Evasão: uma metodologia para estudo da trajetória dos estudantes na educação superior" tem seu foco sobre grupos de estudantes cuja vulnerabilidade se traduz pela evasão, no contexto das universidades brasileiras. O olhar do estudo é sobre a confiabilidade e a precisão das taxas empregadas pelo Ministério da Educação e pelo Tribunal de Contas da União em políticas para controle e acompanhamento da trajetória universitária dos estudantes.

"Professores: quem são, onde trabalham, quanto ganham" apresenta um retrato sobre professores brasileiros, a partir de dados que caracterizam sua quantidade, salários, impactos e potenciais em sistema de ensino, refletindo sobre possíveis caminhos para aumentar a eficiência e a eficácia das redes públicas de ensino, e, possivelmente, também da rede privada.

A seção Página Aberta apresenta "Escola sem Partido: para quem?", que problematiza o Projeto de Lei (PL) "Escola sem Partido", apontando possíveis paradoxos, ambiguidades e dicotomias inerentes a perspectivas que objetivam conferir, à educação, um caráter neutro. Discute, a partir de referencial teórico calcado em Bourdieu, as polêmicas em torno do projeto e sua centralidade nas redes sociais e veículos de imprensa.

A partir da leitura dos artigos, algumas reflexões podem ser tecidas.

Em primeiro lugar, observa-se que programas e políticas acabam por esbarrar em dificuldades que incluem insatisfação de professores, baixos salários e conflitos culturais, com a presença de sujeitos com culturas plurais, incluindo, por exemplo, imigrantes, culturas estas, muitas vezes, dissonantes do currículo oficial e percepções negativas a eles associadas, prejudicando o clima escolar. Ainda que planos para a integração destas identidades marginalizadas possam ocorrer em países europeus e no Brasil, existe a relevância do preparo e da motivação dos atores escolares como aspectos centrais para fazer face à violência escolar, para além das ações propostas e empreendidas por essas políticas.

Em termos históricos, para além da reconstrução documental de uma perspectiva de educação datada, com castigos corporais e outras práticas violentas, é necessário reconhecer que a expansão do acesso à escola pública promoveu a presença de classes populares, o convívio de diferentes culturas e a compreensão da escola como lócus de cruzamento dessas culturas, com suas contradições, conflitos e potenciais. Nesta perspectiva, como contraponto a punições físicas para a manutenção da disciplina escolar, fica a necessidade de organização de trabalho 
coletivo para a construção do conhecimento, com a presença de conselhos, espaços de negociação e renegociação de regras e o protagonismo de docentes para o combate à indisciplina, por intermédio do diálogo, de modo a criar um etos efetivamente multicultural.

Da mesma forma, em termos de educação superior, também o processo de expansão nas últimas décadas, leva à sua centralidade em termos de qualificação profissional e redução das desigualdades sociais, aliando qualidade e inclusão social. Neste sentido, movimentos de avaliação e acreditação, ainda que relevantes, devem ser acompanhados por processos que valorizem a diversidade institucional, as visões e missões que esta diversidade enseja. Movimentos em rede, nacionais e internacionais, são apontados, como perspectivas contra-hegemônicas avaliativas para a as instituições de ensino superior.

Ressalta-se, ainda, que a importância da avaliação pode ser reconhecida, também, no contexto da avaliação da aprendizagem propriamente dita. O processo de diálogo, particularmente em uma visão de currículo centrado no aluno, é central para processo de inclusão. Neste sentido a avaliação é considerada parte desta referida visão, para que os estudantes se sintam como membros ativos de seu desenvolvimento e, desta forma, apresentem aprendizagem significativa, fator decisivo para o sucesso e para a inclusão.

A análise crítica de políticas de avaliação do desempenho das instituições, bem como de retenção e evasão estudantil, que acabam por priorizar o cálculo de custos em detrimento da qualidade da atividade acadêmica, são objeto de crítica, nesta perspectiva. Neste sentido, urge que os indicadores de avaliação levem em conta as trajetórias cada vez mais complexas dos alunos, compreendidos como pessoas físicas, singulares e não apenas dados numéricos para cálculos financeiros, de modo a minimizar processos de exclusão via retenção ou evasão.

Identificadores primários que resultam em indicadores poderiam se referir aos estudantes, individualmente, o que pode, inclusive, minimizar erros como os que categorizam, como evasão estudantil, fatos relacionados à troca de cursos e instituições por ocasião do Sistema de Seleção Unificado ( $\mathrm{SiSu}$ ) quando, na verdade, tais estudantes permanecem no Ensino Superior - o que não seria capturado pelos processos mais homogeneizadores de avaliação, demonstrando, mais uma vez, o valor de avaliações que levem em conta a diversidade cultural.

Estudar experiências avaliativas contra-hegemônicas, assim como pesquisas históricas que versam sobre reformas educativas democráticas pode ser um 
caminho que acrescenta na produção do conhecimento para a diversidade e a inclusão. Uma ilustração é aquela que buscou, em 1947, no Chile, promover ensino com metodologia dita pragmática de conhecimento que tornava o sujeito/ estudante protagonista de sua construção de conhecimento, no marco de um projeto político de igualdade social.

A relevância de experiências concretas, em sua historicidade, dá-se no sentido de mostrar a centralidade de um trabalho político local de articulação cultural com a comunidade. Na perspectiva da valorização da diversidade de sujeitos e instituições educativas, torna-se central que sejam inseridos tanto a escola como seus atores no contexto político local, mostrando possibilidades de conexão das instituições educacionais com políticas ressignificadas a nível local e comunitário, em prol da emancipação e qualificação de grupos marginalizados.

A educação superior, ao mesmo tempo, não poderia se eximir de preparar estudantes de modo a qualificá-los para o mercado de trabalho, dentro das especificidades dos diversos programas. Entretanto, mais uma vez, para que tais experiências possam ser inclusivas, trata-se de tentar desenvolver modelos que articulem competências ditas tecnológicas com as culturas, visões de mundo, motivações, aspectos cognitivos, ações e atitudes reflexivas e avaliativas, por parte dos estudantes. É importante que tais programas não caiam na cilada de deixar de lado, em prol exclusivamente de competências demandadas pelas indústrias, a especificidade da universidade como formadora de sujeitos críticos e pensantes, atentos à diversidade e à justiça, em todas as áreas do saber.

Outro caminho para uma educação para a diversidade e a inclusão social dáse no contexto de projetos de alfabetização. Neste sentido, políticas públicas educacionais tais como o PNAIC buscam mitigar dificuldades na alfabetização de todos os alunos dos anos iniciais, no horizonte, portanto, da democratização do ensino e da inclusão educacional. Entretanto, ainda que os estudos sejam relevantes, poderiam ser enriquecidos com análises que considerassem ações articuladas dentro e fora das escolas que contribuíssem para o sucesso da alfabetização. Tais estudos poderiam explorar, por exemplo, consequências dessas políticas no trabalho docente efetivo em sala de aula, bem como possíveis recontextualizações e hibridizações das mesmas nos níveis meso e micro, assim como problematização dos sentidos de categorias presentes nos discursos e textos da política. O diagnóstico de potenciais e reflexões não só sobre políticas nacionais com intenções de promover educação/ alfabetização de qualidade a grupos vulneráveis, como também sobre a produção do conhecimento específica sobre estas mesmas políticas amplia o 
escopo de nossas análises, favorecendo a potencialização de mecanismos de reconhecimento da pluralidade e de atendimento à mesma.

No âmbito macro, projetos de lei como "Escola sem Partido" merecem análise cuidadosa. Sob a argumentação em prol da liberdade de pensamento e da não doutrinação de estudantes, corre-se o perigo de se recair, justamente, em controle e patrulhamento de professores e de conteúdos de ensino, comprometendo a liberdade de expressão.

Mais uma vez, a grande questão seria: em que medida a escola e o ensino superior devem buscar valorizar a pluralidade cultural e a diversidade de ideias, de modo a permitir diálogos e o confronto de perspectivas diversas, sem que se caia no pensamento único ou no cerceamento aos que pensam de forma diferente de valores vigentes?

Tais ideias ensejam outras reflexões, como a importância da formação inicial e continuada de professores de modo a valorizarem a pluralidade de identidades discentes e fomentarem um ambiente desafiador de preconceitos e expressões violentas contra aquele percebido como " o outro". Também, outros estudos poderiam ampliar o olhar sobre a indisciplina, focalizando contextos mais amplos que acabam por transbordar para as escolas, requisitando ações coordenadas que complementem aquelas dos professores e gestores educacionais.

O conjunto de estudos aqui retratados neste número da Revista Ensaio oferecem, pois, um interessante panorama, no Brasil e no exterior, de programas e políticas educacionais voltadas a grupos marginalizados, identificando, também, do ponto de vista histórico, visões que impregnaram práticas educacionais, ilustrando aquelas que deram certo e outras que não devem ser repetidas, na perspectiva da educação democrática, inclusiva e de valorização da diversidade.

Trata-se de mitigar polarizações, episódios de violência, presentes no contexto da ampliação de situações de conflito verificadas em escolas e exacerbadas pela internet, por meio de cyberbullying. Neste sentido, currículos multiculturais, bem como ações, políticas e programas que incluam apoio a alunos e famílias, visitas a domicílios e outras medidas que visam aproximar a escola dos pais e familiares, bem como políticas a nível macro de melhoria das condições de vida da população podem ser articuladas para que a diversidade e a inclusão se concretizem. 
Políticas educacionais que, ainda que partam de perspectivas mais amplas, ofereçam, também, possibilidades de ressignificações e articulações locais, podem apresentar potenciais de superação de desigualdades e de promoção de ambientes educacionais estimulantes, inclusivos, multiculturais e democráticos.

Para tal, a qualificação e a formação continuada dos atores educacionais têm sido apontadas como um possível caminho para que, do ponto de vista intraescolar, possa ser incentivada a tradução das políticas mais amplas em termos concretos, particularmente no que tange às iniciativas no horizonte da democratização e inclusão educacional.

\section{Referências}

CANDAU, V. M. F. \& MOREIRA, A. F. B. (orgs.), Multiculturalismo: diferenças culturais e práticas pedagógicas. Petrópolis, RJ: Vozes, 2008.

IVENICKI, A. Multiculturalismo e formação de professores: dimensões, possibilidades e desafios na contemporaneidade. Ensaio: Avaliação e Políticas Públicas em Educação, v. 26, n. 100, p. 1151-67, 2018. https://doi.org/10.1590/s0104-40362018002601186

LOPES, A. C., Democracia nas políticas de currículo. Cadernos de Pesquisa, v. 42, n. 147, p. 700-15, 2012. https://doi.org/10.1590/S0100-15742012000300003

RANNIERY, T.; MACEDO, E., Políticas do vivível: diferença, teoria e democracia por vir. In: LOPES, A. C.; OLIVEIREA, A. L. A. R. M.; OLIVEIRA, G. G. S. de (Orgs.). Os gêneros da escola e o (im)possível silenciamento da diferença no currículo. Recife: Ed. UFPel, 2018. p. 21-50.

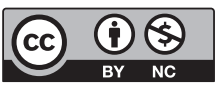

\section{Informações da autora}

Ana Ivenicki: PhD em Educação pela University of Glasgow; Professora Titular da Faculdade de Educação da Universidade Federal do Rio de Janeiro; Editora Associada da revista Ensaio: Avaliação e Políticas Públicas em Educação da Fundação Cesgranrio e Pesquisadora 1A do CNPq. Contato: aivenicki@gmail.com 